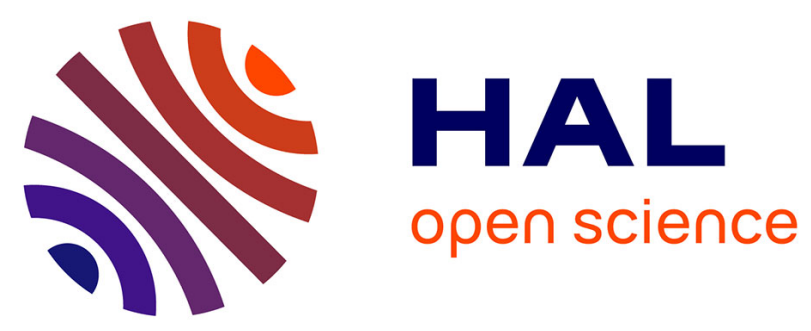

\title{
Usage-based account of the acquisition of liaison: evidence from sensitivity to plural / singular orientation of nouns
}

Céline Dugua, Elsa Spinelli, Jean-Pierre Chevrot, Michel Fayol

\section{- To cite this version:}

Céline Dugua, Elsa Spinelli, Jean-Pierre Chevrot, Michel Fayol. Usage-based account of the acquisition of liaison: evidence from sensitivity to plural / singular orientation of nouns. Journal of Experimental Child Psychology, 2009, 102, pp.342-350. 10.1016/j.jecp.2008.07.006 . hal-00718014v2

\section{HAL Id: hal-00718014 \\ https://hal.science/hal-00718014v2}

Submitted on 19 Jan 2013

HAL is a multi-disciplinary open access archive for the deposit and dissemination of scientific research documents, whether they are published or not. The documents may come from teaching and research institutions in France or abroad, or from public or private research centers.
L'archive ouverte pluridisciplinaire HAL, est destinée au dépôt et à la diffusion de documents scientifiques de niveau recherche, publiés ou non, émanant des établissements d'enseignement et de recherche français ou étrangers, des laboratoires publics ou privés. 
Dugua, C., Spinelli, E., Chevrot, J.-P \& Fayol, M. (2009). Usage-based account of the acquisition of liaison: evidence from sensitivity to plural / singular orientation of nouns, Journal of Experimental Child Psychology, 102, 342-350.

\section{Usage-based account of the acquisition of liaison: evidence from sensitivity to plural / singular orientation of nouns}

\section{Céline Dugua (1), Elsa Spinelli (2), Jean Pierre Chevrot (3) \& Michel Fayol (4)}

(1) Laboratoire LLL/Coral, Université d'Orléans, France

(2) Laboratoire de Psychologie et NeuroCognition

Université Pierre Mendès France, Grenoble, France

Institut Universitaire de France

(3) Laboratoire Lidilem, Université Stendhal, Grenoble, France

(4) Laboratoire Lapsco, Clermont-Ferrand, France

Short title: Acquisition of liaison

Corresponding author: Céline Dugua

E-mail address: celine.dugua@univ-orleans.fr

Phone: +33(0)2-38-49-24-13

Fax: +33(0)2-38-41-47-12 


\begin{abstract}
This study investigates whether the production and the recognition of liaison sequences in children depend on the singular/plural orientation of nouns. Certain nouns occur more frequently in the plural (e.g., arbre "tree") whereas others are found more often in the singular (e.g., arc-en-ciel "rainbow"). In the input, children more frequently encounter these pluraloriented nouns after determiners which indicate plurality (e.g., les, des, "the", deux, "two", etc.) and which are often associated with a /z/ liaison [døzarbR],"two trees". In experiment 1 , 122 children (aged from 3;2 to 6;3) were asked to produce nominal phrases with either /z/ liaisons (i.e., in plural contexts like deux ours [døzurs],"two bears") or with /n/ liaisons (i.e., in singular contexts like un ours [ãnuRs],"one bear"). We found correlations between the plural-orientation of the nouns and (1) the probability that they will be preceded by an incorrect /z/ liaison in singular contexts (2) the probability that they will be preceded by a correct /z/ liaison in the plural context. This result was however restricted to the younger children. In experiment 2, 20 children (aged from 5;5 to 6;3) were asked to monitor target words in auditorily presented sentences. The results showed shorter responses times for singular-oriented nouns when preceded by singular determiners than when preceded by plural determiners. Conversely, plural-oriented nouns were responded to faster when preceded by a plural determiner than by a singular determiner. Results are discussed within the framework of a two-stage model of liaison acquisition recently proposed by Chevrot, Chabanal and Dugua (2007) and Chevrot, Dugua and Fayol (submitted).
\end{abstract}


Liaison in French consists in the production of a consonant between two words (e.g., /z/ in deux ours [døzuRs],"two bears"). For the liaison to appear, the right-hand word (hereafter Word2) has to begin with a vowel when spoken in isolation ([uRs], "bear"). When this liaison consonant is produced, it generally forms a syllable with the initial vowel of the following word. For example, the sequence deux ours ("two bears") is syllabified [dø.zuRs]. Because lexical segmentation processes make use of the probable correspondence between syllabic boundaries and word boundaries (Content, Kearns \& Frauenfelder, 2001), the resyllabification process of liaison creates a tricky situation for French young children since they hear various forms of Word2 depending on the preceding Word1. For example, they can be confronted to [nuRs] in un ours ("one/a bear"), [zuRs] in les ours ("the bears"), [tuRs] in petit ours ("little bear").

Liaison acquisition is indeed not easy as it takes around six years for French children to master liaison. In a case study, Chevrot and Fayol (2000) and Dugua (2006) analysed the liaisons errors produced by a little girl (Sophie), aged from $2 ; 1$ to $6 ; 4$. The largest proportion of errors is observed around the age of 3. Sophie's liaison errors can be divided into 2 main categories: addition errors (e.g., [mamãnuRs] maman ours ("mummy bear") instead of [mamãuRs]), and replacement errors ([gRãnekleR] grand éclair ("great flash of lightning") instead of [gRãtekleR]).

Dugua (2006) evaluated the development changes of liaison production performance in determiner+noun sequences (e.g., un ours "a/one bear", deux ours, "two bears") of 200 children between 2;4 and 6;1. Over time, correct productions increase from 36\% at 2-3 years to $83 \%$ at 5-6 years, while replacement errors decrease from $44 \%$ to $4 \%$. This pattern of production performance was confirmed by a longitudinal study on 20 children tested five times from the age of 2 to 6 years (Dugua, 2006).

From the first approach of Schane (1968), the modelling of liaison has proved to be an unavoidable test for all of the generative theories of adult phonology (Tranel, 2000). With regard to its acquisition, Wauquier-Gravelines \& Braud (2005) have proposed a conception within the generative framework of autosegmental phonology. They assume that liaison errors between a determiner and a noun are one of the first manifestations indicating that prosodic positions are independent of the phonetic content of the segments. In line with the principle that syllables with an onset are preferred, a prosodic position $\mathrm{C}$ corresponding to the liaison 
would then be associated with the syllabic onset of the noun. In contrast to this conception which assumes that the children early encode an abstract prosodic position, Chevrot, Dugua and Fayol (submitted) and Chevrot, Chabanal and Dugua (2007) have recently proposed an exemplar-based model of liaison acquisition between determiner and noun, in line with Bybee's view in adults (2001). It is assumed that early on, children memorize concrete chunks of speech (Tomasello, 2003), some of which contain determiner-noun sequences including a liaison. When segmenting these chunks, children would favor the presence of a consonant at the initial of the Word2 (les ours 'the bears' would be segmented as /le/ + /zuRs/). They would cope with the variation of the liaison in the input by memorizing multiple concrete exemplars of the same Word2 (/nuRs/, /zuRs/, /tuRs/ for ours). Since they simultaneously generalize schemata based on the determiner, this model weaves together progress in the production of liaisons, segmentation of new words and development of item-based constructions.

In the first stage of the model (around 2-4 years old), children segment lexical exemplars of each Word2. Given that the lexical segmentation process makes use of the probable correspondence between syllabic boundaries and word boundaries (Mattys \& Jusczyk, 2001), they attach the different liaison consonants preceding the Word 2 to this word, thus resulting in several exemplars of each Word2: /nuRs/, /tuRs/, /zuRs/ for ours "bear". The segmentation of the Word 2 is correlative with the segmentation of the Word 1 which constitutes the stable lexical item in a large number of chunks. The determiner could therefore become the concrete element in schemata taking the form $u n+\mathrm{X}$, les $+\mathrm{X}$, etc.

A second stage (from 4 years old) is characterized by a more abstract structure which generalizes the relation between a specific Word1 (e.g., les [le]) and a class of variants of the Word2s (e.g., exemplars beginning with $[\mathrm{z}]$ ). From determiner+noun sequences including a liaison (/lezurs/, /lezan/, /lezami/, "the bears", "the donkeys", "the friends"), children generalize specified schemata (les $+/ \mathrm{zX} /$ ) that include information about the liaison. More precisely, these schemata specify the nature of the lexical variant which should fill the slot following a specific Word1 (in the case of les $+/ \mathrm{zX} /$ : an exemplar beginning with /z/ should follow the Word1 les). These schemata enable children to produce correct liaisons which they have never heard.

Central to this exemplar-based account of liaison acquisition is the role of frequency. Children learn the correct relations between the Word1s and the Word2 exemplars through exposure to the well-formed sequence ( $u n+/ \operatorname{naRbR} /$, deux $+/ \mathrm{zaRbR} /)$. Hence, if a Word1 
frequently co-occurs with a Word2 (e.g., un + âne in the sequence un âne [œ̃nan] with the /n/ liaison), it should lead to a high level of correct liaison production. Moreover, this should render the exemplar/nan/ more available to the production/recognition system than other exemplars such as /zan/. Some nouns are more often encountered at the plural form (e.g., indiens, "indians") whereas other nouns are more often encountered in singular (e.g., arc-enciel, "rainbow"). It follows that children more frequently encounter plural-oriented nouns like indiens after determiners which indicate plurality (les, des, "the", deux, "two", etc.) and which are often associated with a /z/ liaison (Morin \& Kaye, 1982). Similarly, children encounter singular-oriented nouns like arc-en-ciel more frequently after singular determiners (un, "one/a", etc.) often associated with a /n/ liaison.

The model thus predicts an influence of the plural/singular orientation of nouns on the liaison production of young children but not of older children. As a matter of fact, the general schemata of the first stage $(u n+\mathrm{X}$, les $+\mathrm{X})$ provide no constraint on the nature of the liaison consonant following a Word 1 and then allow a frequency effect. Experiment 1 was designed to test this prediction.

\section{Experiment 1}

Children were asked to produce short phrases with either /z/ liaisons (i.e., plural phrases like deux ours [døzurs],"two bears") or with /n/ liaisons (i.e,. singular phrases like un ours [ãnuRs],"one bear"). We evaluated 1) whether the rate of correct /z/ and /n/ productions depended on the singular/plural orientation of nouns and 2) whether replacement errors followed the singular/plural orientation of nouns.

Method

\section{Participants}

Participants were 122 native French-speaking children aged from $3 ; 2$ to $6 ; 3$ ( $M=4 ; 8$ years, $\mathrm{SD}=8.4$ months), 70 girls and 52 boys, from middle-classe. Three age-groups were formed: age-group1: 29 children aged from 3;2 to 4;1 ( $\mathrm{M}=3 ; 9$ years, $\mathrm{SD}=3.1$ months); agegroup2: 48 children aged from 4;2 to 5;0 ( $\mathrm{M}=4 ; 7$ years, $\mathrm{SD}=3.3$ months); age-group3: 45 children aged from 5;1 to $6 ; 3(\mathrm{M}=5 ; 5$ years, $\mathrm{SD}=3.6$ months). Hence all children were tested before they start learning to read/ write in order to avoid any effect of literacy on liaison performances. 


\section{Stimuli}

Target words were selected under the constraint that they were masculine, vowelinitial, picturable and frequent enough to be known by 3 years old children. Hence, eight target nouns were selected following these criteria. Four were more frequent at the plural form than the singular one - e.g., arbre ("tree") - and four were more frequent at the singular form than the plural one - e.g., ours ("bear"). The plural/ singular polarization of these targets was obtained by the means of a pre-test in which adult participants (70 native French-speaking students) had to choose between two sequences (e.g., un ours "one/a bear", des ours "some/ bears" $^{1}$ ), the one that seems to be the more frequent. For each noun we established a ratio which gave the tendency for the noun to be plural (see details in appendix). There were also five masculine consonant-initial filler targets - e.g., camion ("truck") - for which no liaison consonant is produced after determiners (e.g., un camion [õkamjõ], deux camions [døkamjõ]).

\section{Procedure}

Children were tested individually at school and were asked to perform a picture naming task. Pictures were composed of items that were represented in one or two exemplars. The experimenter asked the child "what is there in this picture?" and the child had to give an answer of the type "un + Word2" (e.g., "one bear") or "deux + Word2" (e.g., "two bears"). After each target presentation, we alternated presentation of filler sequences. The presentation order of target words was randomized across children.

\section{Results and discussion}

Percentages of correct productions and of replacement errors for each age-group are reported in table 1 . Analyses of the production data showed that both correct productions and replacement errors globally varied with age (Kruskall-Wallis: $\mathrm{H}=16.168, \mathrm{p}=0.0003$; Kruskall-Walis: $\mathrm{H}=15.640, \mathrm{p}=0.0004$ respectively). Correct productions increased significantly between age ranges 1 and 2 (Mann-Whitney: $U=373.5, p=0.0006$ ) but not between age ranges 2 and 3 (Mann-Whitney: $U=1000.5, p=0.5210$ ). Moreover, replacement errors decreased significantly between age ranges 1 and 2 (Mann-Whitney: $U=501, p=$ 0.0137 ) but also between age ranges 2 and 3 (Mann-Whitney: $U=904, p=0.0396$ ). 
We assessed whether the singular/plural orientation of nouns affected the children' correct productions and their errors production. We thus established two ratios, which gave the orientation of production towards the /z/ liaison, which is associated with the plural determiner. The first ratio based on the correct productions was obtained this way: Number of correct productions with $/ z / /$ number of correct productions. The second ratio was based on the replacement errors and was obtained by calculating the Number of replacement errors in $/ z / /$ number of $/ z /$ and $/ n /$ replacement errors. Ratios close to 1 show a bias towards /z/ liaison, whether correct or wrong.

For each age-group, correlations between the singular/plural orientation of the nouns and the orientations of the responses toward /z/ liaison (both correct responses and errors) were calculated. These correlations are reported in table 2.

$<$ insert table 2 around here $>$

Analyses of the correlations showed an effect of the singular/plural orientation of nouns in the children' productions in the first age-group. The more often a noun is encountered at the plural form (e.g., arbre, "tree"), the more the /z/ liaison following the plural determiner deux (e.g., in deux arbres [døzaRbR], "two trees") is correctly produced. Moreover, these plural-oriented nouns more often induced /z/ liaison errors after the determiner un. In other words, children would be more likely to make errors such as un zarbre ([œ̃zaRbR]) in which the plural liaison consonant incorrectly surfaces after a singular determiner in front of a plural-oriented noun. The effect of the singular/plural orientation of nouns in the children' productions was only marginally significant in the second age group and from the age of 5 , no effect was observed.

Results of this production experiment are in line with the predictions of the model of liaison acquisition. Children of 3-4 years are sensitive to exemplars frequency. They therefore produce more correct liaisons in Word1-Word2 sequences which they hear frequently because they consist in a plural-oriented noun following a plural determiner. Moreover, as the general schemata of first stage $(u n+\mathrm{X})$ provide no constraint as for the nature of the exemplars that should follow the Words1, high frequency exemplars are also favored in unexpected contexts (e.g., [zaRbR] is produced after un), thus resulting in replacement errors. Five-6 years' children productions no longer correlate with nouns number orientation. This latter result is also compatible with the two-stage model and illustrates the emergence of specified schemata 
of the type $u n+n X$ in which Word 2 exemplars are constrained by Words 1 . When such specified schemata are operative, exemplars frequency should not influence production because the schema determines the form that ought to be produced. However, we assume that lexical units that were frequently produced (i.e., high frequency exemplars) should remain more available in the lexicon. Consequently, for older children there should be memory traces of the exemplars that frequently occurred in earlier productions. We tested this prediction in a perception experiment in which 5-6 years old children had to monitor singular (arc-en-ciel) and plural (indien) oriented nouns preceded by singular (un) or plural (les) determiners.

\section{Experiment 2}

In this experiment, children were asked to monitor target words in auditorily presented sentences. If we assume memory traces of high frequency exemplars in the lexicon, those exemplars should be more easily available. We thus predicted that nouns that are more often encountered at the plural form (e.g., indien, "indians") should be better detected after the

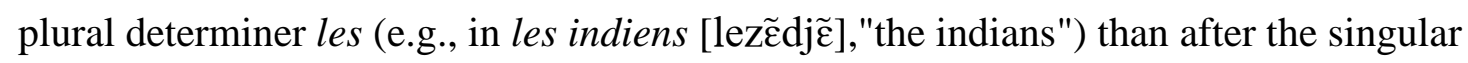

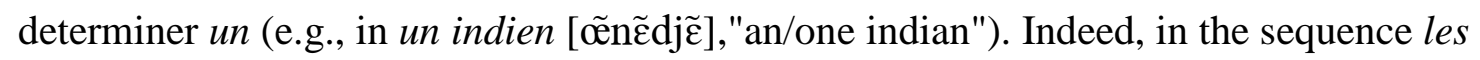

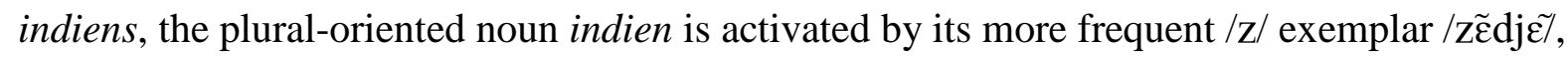

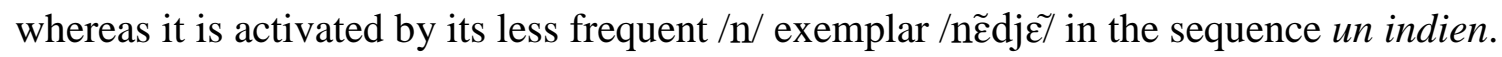
Conversely, singular-oriented nouns (e.g., arc-en-ciel, "rainbow") should be better detected after the singular determiner $u n$ than after the plural determiner les.

\section{Method}

\section{Participants}

Twenty preschoolers participated in the experiment. All participants were native speakers of French. Their average age was 5 years, 10 months (range 5;5 to 6;3). Stimuli

The stimulus set was composed of 10 masculine vowel-initial target words. Five were more frequent at the plural form than the singular one - e.g., indien ("indian") - and the other five were more frequent at the singular form than the plural one - e.g., arc-en-ciel ("rainbow"). The plural/singular polarization of these targets was obtained by the means of a pre-test similar to that of experiment 1 on adult participants (70 up to 104 native French-speaking students, depending on the items). 
Experimental trials: Targets were presented in their plural and singular forms. Because singular/plural distinction is silent in the auditory modality, singular/plural form is given by the determiners preceding the targets (either un or les). Two carrier sentences were created for each target at the singular form (i.e., with the determiner $u n$ ) and at the plural form (i.e., with the determiner les), one in which the target occurred at the beginning of the sentence and the other one with the target occurring later in the sentence. Hence, there were 40 experimental trials.

Filler trials: Target-present trials: Sixty carrier sentences containing the targets were created in order that targets were heard with preceding adjectives instead of determiners (e.g., joli, "nice", petit, "little" or super, "super"). Target-absent trials: One hundred sentences were created so that they did not contain the target but contained the determiners of the experimental trials (un, les) and the adjectives of the filler-target-present trials (joli, petit, super). Hence, 10 blocks of twenty sentences were created, one block for each target containing as many target present trials than target absent trials.

\section{Procedure}

Participants were tested individually, at school, in a quiet room. They were asked to detect a target word in a sentence. A picture of the target was first displayed at the centre of a computer screen and children were asked to name it. This picture remained on the screen during the entire block. The spoken sentences were then presented auditorily at a comfortable sound level through headphones. The participants were instructed to press the response button as soon as they heard the target word or to do nothing if the target was not present. Response latencies were recorded. The experiment was controlled by E-prime. The target word remained the same during the entire block. Within each block, the 20 sentences appeared randomly. The order of blocks presentation was also randomized for each subject. The experiment began by 2 practice blocks of 6 sentences.

\section{Results and discussion}

Mean Reaction Times (RT) from word onsets ${ }^{2}$ and Standard Deviation (SD) for the targets presented in the two conditions are presented in table 3. For experimental targets, there were $1.4 \%$ of omission collapsed on all conditions and $1 \%$ of false alarms (participants responding before the targets) which were removed from the analyses. Moreover, RTs shorter than $250 \mathrm{~ms}$, RTs above and below 2SD were also removed leading to the exclusion of $1.5 \%$ of the data. Hence altogether, there were $3.9 \%$ of the data removed from the analyses. The results were evaluated using two-way repeated measures analyses of variance (ANOVAs). 
The main factors were determiner type (singular, un vs plural, les) and number orientation (plural oriented, singular oriented), both within subject factors.

< insert table 3 around here >

Analyses of RTs revealed no main effect of the determiner type, $F_{(1,19)}=1.4$, ns.; $\eta^{2}=$ .07. The effect of the number orientation was marginally significant, $F_{(1,19)}=3.25, p=.084, \eta^{2}=$ .15. However, the interaction between these two factors was significant, $\mathrm{F}_{(1,19)}=9.1, \mathrm{p}<.01 ; \eta^{2}$ $=.32$. Planned comparisons showed shorter responses times for singular-oriented nouns when preceded by singular determiners $(798 \mathrm{~ms})$ than when preceded by plural determiners $\left(889 \mathrm{~ms} ; \mathrm{F}_{(1,19)}=6.74, \mathrm{p}<.05 ; \eta^{2}=.26\right)$. Conversely, plural-oriented nouns were responded to faster when preceded by a plural determiner $(868 \mathrm{~ms})$ than by a singular determiner $(911 \mathrm{~ms})$, but this effect is only marginally significant, $F_{(1,19)}=3.05, p<.09 ; \eta^{2}=.14$. These results show that for singular-oriented words (e.g., âne "donkey"), /n/ exemplars (e.g., /nan/) are more available to the recognition system than /z/ exemplars (e.g., /zan/) and for plural-oriented words, /z/ exemplars are more available than /n/ exemplars. A frequency effect can thus be evidenced for children aged of 5-6 years even though frequency does not affect production at that age.

\section{General discussion}

In this study, we found that production (experiment 1) and recognition (experiment 2) of liaison sequences depended on the singular/plural orientation of nouns. We used singular/plural orientation of nouns as an indicator of liaison initial exemplars frequency in children's input. Our results showed that young children tended to produce more often high frequency exemplars (e.g., zarbre) both in expected and unexpected context, respectively resulting in a correct liaison (deux arbres [døzaRbR], "two trees") or a replacement error (un zarbre [थ̃zaRbR], "one tree"). The first stage of the liaison acquisition model accounts for these results as any exemplar can fill the slot $\mathrm{X}$ in the general schemata "un $+\mathrm{X}$ " or "deux + $X^{\prime \prime}$. Frequent exemplars are thus favored. As for 5-6 years children, specified schemata of the type "un $+n \mathrm{X}$ " or "deux $+z \mathrm{X}$ " are operational. These schemata select exemplars following Words 1 on the basis of their initial consonant and do not allow replacement errors. As a consequence, singular/plural orientation of nouns no longer influences liaison production at that age. However, 5-6 years children remain sensitive to singular/plural orientation of nouns 
in spoken language recognition. In a word monitoring experiment, they were faster at detecting high frequency exemplars (e.g., indien in zindiens) than low frequency ones (indien in nindien). This suggests that frequent lexical exemplars remain more available in the lexicon than low frequency ones even when they are no longer produced in the wrong context. Results of these two experiments are in accordance with the usage-based conception, as they account for the simultaneous presence of multiple exemplars of the nouns and more abstract schemata in the lexicon (Chevrot et al., 2007 ; Chevrot et al., submitted).

More precisely, results of experiment 1 allowed testing one difference that opposes the (generative) autosegmental conception with the exemplar-based conception. In the exemplarbased model, the multiple lexical representation associated with the noun ours is the combinations of a number of concrete sequences - /urs/, /nuRs /, /zurs /, /turs/. The phonetic material corresponding to the liaison consonants specifically belongs to these exemplars. In the autosegmental conception, children assign a phonetic content to an abstract initial position either on the basis of context or by default (Wauquier-Gravelines \& Braud, 2005). This phonetic content is not related to the lexical representation of the noun and does not belong to it. Our data show, however, that there is a relation between the phonetic nature of child liaison before a specific noun and the frequency of the liaisons which precede this noun in the input. If the phonetic content of the liaisons depends indeed on the following noun, it is difficult to imagine that it starts with an abstract position with no phonetic content.

Our results rather support the view that young children memorize several exemplars of the same word starting with different liaison consonants, and that frequency of exposition is central to the construction and the availability of these exemplars. Frequency thus appears to be an important issue in the acquisition of liaison. Given that one liaison context occurs every 16 words in adult speech (Boë \& Tubach, 1992), the phenomenon is sufficiently frequent for children to identify regular patterns in its use. Research on word segmentation has shown that learners can use transitional probabilities between syllables to segment speech into word-like units. For example, Saffran, Aslin, \& Newport (1996) have established that segmentation of words from fluent speech can be accomplished by 8-month-old infants based solely on the statistical relationships between neighbouring speech sounds. Hence, statistical learning is a powerful mechanism and it could be argued that the transitional probability between two words could account for the effect found in experiment 2. Children would detect faster indiens in the sequence des zindiens, not because the exemplar zindiens is more available in the lexicon but because the words des and indiens frequently co-occur. However, the intrusion 
of the most frequent exemplar in the wrong context, such as in the error un zarbre [थ̃zaRbR] (experiment 1), argues in favor of a multiple exemplar view because the sequence zarbre never appears after $u n$ in the input. Nevertheless, statistical learning is involved in exemplar formation, leading to the availability of the more frequent sound sequences encountered in the input. 
References

Boë, L.-J. \& Tubach, J.-P. (1992). De A à Zut: dictionnaire phonétique du français parlé. Grenoble: Ellug.

Bybee, J. (2001). Frequency effects on French liaison. In Bybee, J. \& Hopper, P. (Eds.), Frequency and the emergence of linguistic structure (pp.337-359). Amsterdam, Philadelphia: John Benjamins Publishing Company.

Chevrot, J.-P., Chabanal, D. \& Dugua, C. (2007). Pour un modèle de l'acquisition des liaisons basé sur l'usage: trois études de cas. Journal of French Language Studies, 17, 103-128.

Chevrot, J.-P., Dugua, C. \& Fayol, M. (submitted). Liaison and word segmentation in French: a usage-based account. Journal of Child Language.

Chevrot, J.-P. \& Fayol, M. (2000). L'acquisition de la liaison: enjeux théoriques, premiers résultats, perspectives. Lidil, 22, 11-30.

Content, A., Kearns, R. K. \& Frauenfelder, U. H. (2001). Boundaries versus onsets in syllabic segmentation. Journal of Memory and Language, 45, 177-199.

Dugua, C. (2006). Liaison, segmentation lexicale et schémas syntaxiques entre 2 et 6 ans. Un modèle développemental basé sur l'usage. Thèse de doctorat, Université Stendhal Grenoble3, Grenoble.

Mattys, S. L. \& Jusczyk, P. W. (2001). Do infants segment words or recurring continuous patterns? Journal of Experimental Psychology: Human Perception and Performance, 27, 644-655.

Morin, Y.-C. \& Kaye, J. D. (1982). The syntactic bases for French liaison. Journal of Linguistics, 18, 291-330.

New, B., Pallier, C., Ferrand, L. \& Matos, R. (2001). Une base de données lexicales du français contemporain sur internet: Lexique. L'année psychologique, 101, 447-462.

Saffran, J. R., Aslin, R. N. \& Newport, E. L. (1996). Statistical learning by 8-month-old infants. Science, 274, (5294), 1926-1928.

Schane, S. A. (1968). French phonology and morphology. Cambridge: MIT Press.

Tomasello, M. (2003). Constructing a language: a usage-based theory of language acquisition. Cambridge, Massachussetts: Harvard University Press.

Tranel, B. (2000). Aspects de la phonologie du français et la théorie de l'optimalité. Langue française, 126, 39-72.

Wauquier-Gravelines, S. \& Braud, V. (2005). Proto-déterminant et acquisition de la liaison obligatoire en français. Langages, 158, 53-65. 
Table 1: Mean percentages of correct productions and of replacement errors for each age group and for plural-oriented and singular-oriented nouns.

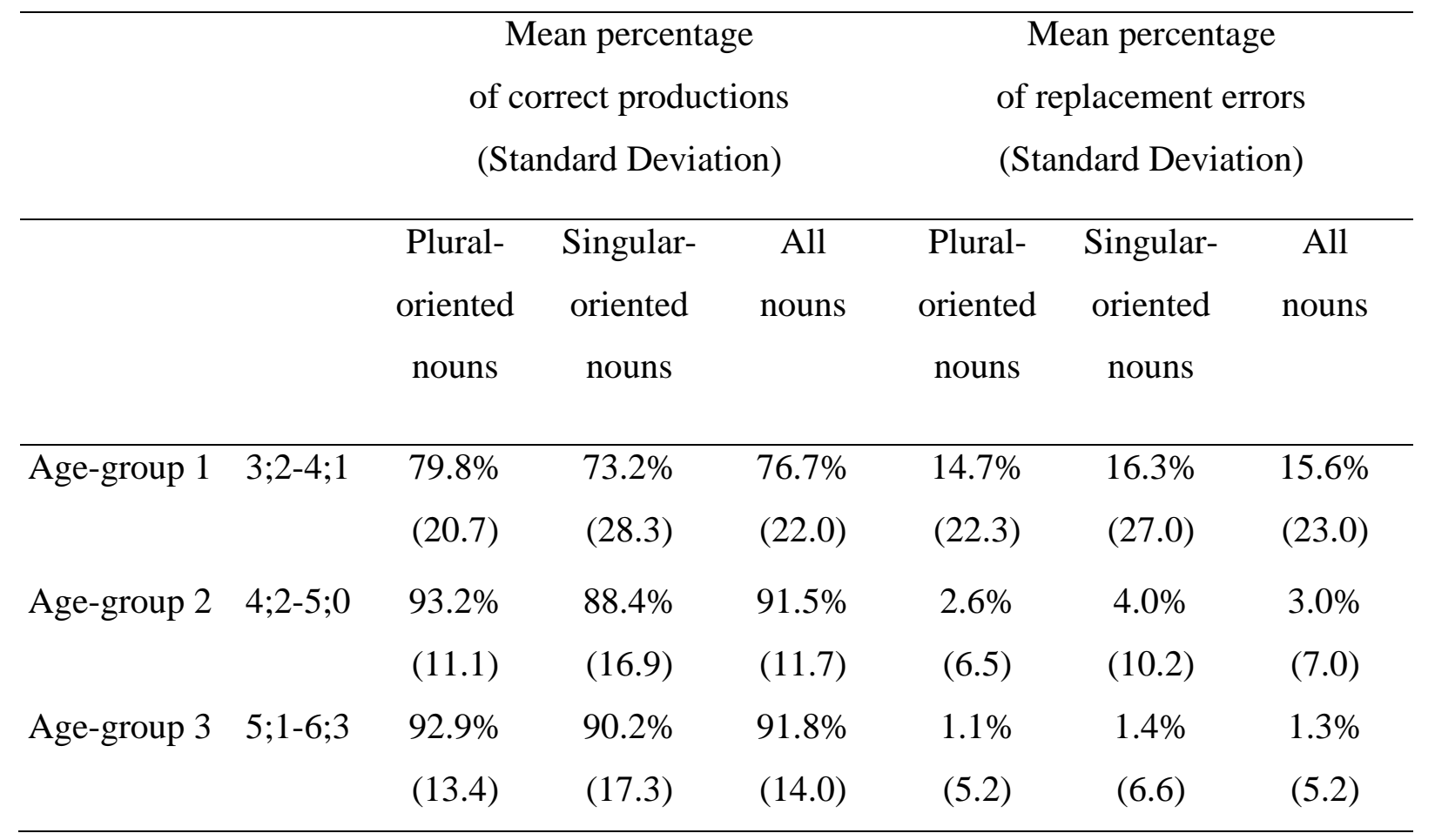


Table 2 : Pearson's correlations between the singular/plural orientation of the nouns and the singular/plural orientations of the responses for each age group.

Correlations between the orientation of the nouns and the orientations of the correct responses
Correlations between the orientation of the nouns and the orientations of the replacement errors

\begin{tabular}{llll}
\hline Age-group 1 & $3 ; 2-4 ; 1$ & $\mathrm{r}=.775, \mathrm{p}=.024(\mathrm{n}=8)$ & $\mathrm{r}=.713, \mathrm{p}=.047(\mathrm{n}=8)$ \\
Age-group 2 & $4 ; 2-5 ; 0$ & $\mathrm{r}=.666, \mathrm{p}=.071(\mathrm{n}=8)$ & $\mathrm{r}=.715, \mathrm{p}=.071(\mathrm{n}=7)$ \\
Age-group 3 & $5 ; 1-6 ; 3$ & $\mathrm{r}=-.413, \mathrm{p}=.309(\mathrm{n}=8)$ & $\mathrm{r}=.485, \mathrm{p}=.330(\mathrm{n}=6)$ \\
\hline
\end{tabular}


Table 3: Mean Reaction Times in Milliseconds (RT) and Standard Deviation (SD) for responses to the targets in the two conditions.

\begin{tabular}{llll}
\hline & $\begin{array}{l}\text { Plural } \\
\text { determiner }\end{array}$ & $\begin{array}{l}\text { Singular } \\
\text { determiner }\end{array}$ & Effect \\
\hline Plural-oriented & & & \\
RT (ms) & 868 & 911 & $42 \mathrm{~ms}$ \\
SD & $(209)$ & $(240)$ & \\
\hline Singular-oriented & & & $-91 \mathrm{~ms}$ \\
RT (ms) & 889 & 798 & \\
SD & $(252)$ & $(255)$ & \\
\hline
\end{tabular}


Foot notes :

${ }^{1}$ Nouns were integrated in two types of sequences: plural ones and singular ones. The first included determiners les "the $\mathrm{plural}_{\text {" }}$ and des "some $\mathrm{plural}$; and the second included the determiners le/lall' "the" and un "a/one". Each noun was judged in two modalities: 1) with singular vs plural definite determiners (e.g., l'âne vs les ânes; "the donkey vs the plural donkeys"); and 2) with singular vs plural indefinite determiners (e.g., un ami "a/one friend" vs des amis "friends/ some friends"). The plural/singular presentation order was crossed with the determiners conditions. For example, if the first presentation of the noun ours ("bear") was the opposition l'ours vs les ours (singular-plural, definite) the second was des ours vs un ours (plural-singular, indefinite).

${ }^{2}$ Because response latencies were recorded from the beginning of the sentences, cues were placed at the onset of target words as identified by visual inspection of the waveforms and spectrograms using Cool Edit Pro (cue tagging was double checked by a professional phonetician). Reaction times were then computed by subtracting durations from beginnings until target onsets to responses latencies. 
Appendix

Material used in Experiment 1 and Experiment 2. Ratios towards the plural were calculated this way: Number of plural choices / (number of plural + number of singular choices). They are given by the pre-tests (a ratio close to 1 means that an item is judged to be plural oriented). Frequencies (occurrences per million) given by the French data base "Lexique" (New, Pallier, Ferrand \& Matos, 2001) confirm the plural/singular polarizations obtained by the ratios except for one item of experiment 2 (enfant).

Authors' note

\begin{tabular}{cccc}
\hline Targets & $\begin{array}{c}\text { Frequency at the } \\
\text { singular form }\end{array}$ & $\begin{array}{c}\text { Frequency at the } \\
\text { plural form }\end{array}$ & $\begin{array}{c}\text { Ratio towards the } \\
\text { plural }\end{array}$ \\
\hline
\end{tabular}

\section{Experiment 1}

\begin{tabular}{cccc}
\cline { 2 - 3 } Oeil (plural-oriented) & 278.51 & 955.74 & 0.791 \\
Oeuf (plural-oriented) & 20.34 & 29.80 & 0.741 \\
Arbre (plural-oriented) & 67.16 & 141.49 & 0.604 \\
Escargot (plural-oriented) & 2.84 & 4.32 & 0.536 \\
Ours (singular-oriented) & Not available & Not available & 0.307 \\
Elephant (singular-oriented) & 8.92 & 6.01 & 0.293 \\
Avion (singular-oriented) & 46.82 & 31.22 & 0.196 \\
Ordinateur (singular-oriented) & 2.30 & 1.96 & 0.051
\end{tabular}

\section{Experiment 2}

\begin{tabular}{cccc}
\cline { 2 - 3 } Abricot (plural-oriented) & 1.15 & 1.35 & 0.613 \\
Indien (plural-oriented) & 0.47 & 3.65 & 0.762 \\
Ongle (plural-oriented) & 10.14 & 35.34 & 0.746 \\
Oiseau (plural-oriented) & 47.97 & 65.14 & 0.667 \\
Enfant (plural-oriented) & 382.23 & 343.92 & 0.803 \\
Arrosoir (singular-oriented) & 3.04 & 0.54 & 0.078 \\
Ane (singular-oriented) & 14.32 & 4.32 & 0.137 \\
Ange (singular-oriented) & 21.62 & 20.88 & 0.413 \\
Arc-en-ciel (singular-oriented) & 4.39 & 0.54 & 0.036 \\
Avion (singular-oriented) & 46.82 & 31.22 & 0.196
\end{tabular}


This research was partly funded by the Agence Nationale pour la Recherche "Phonlex" under the supervision of Jacques Durand. We thank Nathalie Vallée for her help with the experimental stimuli.

We also thank David F. Bjorklund and two anonymous reviewers for their valuable comments on earlier versions of this manuscript. 